\title{
El crimen de agresión en el Estatuto de la Corte Penal Internacional
}

\author{
José Antonio Burneo Labrín*
}

\section{RESUMEN}

En diciembre de 2017, en el marco del tratado denominado Estatuto de Roma que crea la Corte Penal Internacional, la 16ta. Asamblea de Estados Partes adoptó, por consenso, la Resolución ICC-ASP/16/Res.5, denominada "Activación de la competencia de la Corte respecto del crimen de agresión». En virtud de la referida Resolución, se estableció: i) la definición del crimen de agresión adoptada el año 2010 por la Conferencia de Estados Partes en el Estatuto de Roma, realizada en Kampala (Uganda) ha devenido en aplicable. Asimismo, se reafirma el alcance universal de la sanción penal de dicho crimen, en virtud, de normas jurídicas internacionales no-convencionales, esto es, consuetudinarias o de jus cogens, y ii) se otorga competencia efectiva a un órgano jurisdiccional, la Corte Penal Internacional, a fin de que administre justicia respecto del crimen de agresión.

A continuación, en el presente trabajo se abordará la cuestión de la definición del crimen de agresión en el marco del Estatuto de Roma y su repercusión universal (Sección I), y luego la cuestión de la competencia de la Corte Penal Internacional sobre dicho crimen (Sección II).

Palabras clave: Derecho Penal Internacional, crímenes internacionales, Corte Penal Internacional, jurisdicción penal internacional, crimen de agresión, Estatuto de Roma.

\section{The Crime of Aggression in the Rome Statute of the International Criminal Court}

\section{Abstract}

In December of 2017, within the framework of the Rome Statute that creates the International Criminal Court, the 16th Assembly of States Parties adopted by consensus the Resolution ICC-ASP / 16 / Res.5, entitled «Activation of the jurisdiction of the Court over the crime of aggression». Under the aforementioned Resolution, it was established: (i) the definition of the crime of aggression adopted in 2010 by the Conference of States Parties to the Rome

\footnotetext{
* Profesor del Departamento de Derecho de la PUCP, Lima, Perú. Abogado por la PUCP y doctor en Derecho por la Universidad Católica de Lovaina. Correo electrónico: jaburneo@pucp.edu.pe
} 
Statute, held in Kampala (Uganda) has become applicable. Likewise, the universal scope of the criminal sanction of this crime is reaffirmed, by virtue of non-conventional international legal norms, like customary norms or jus cogens, and (ii) effective jurisdiction is granted to a jurisdictional body, the International Criminal Court, in order to administer justice with respect to the crime of aggression.

In this paper it will be addressed the question of the definition of the crime of aggression under the Statute of Rome and its universal impact (Section I) and, then, the question of the jurisdiction of the International Criminal Court on this crime (Section II).

Keywords: International Criminal Law, international crimes, International Criminal Court, international criminal jurisdiction, crime of aggression, Rome Statute.

\section{Introducción}

Hace unos pocos meses, en diciembre de 2017, en el marco del tratado denominado Estatuto de Roma $(1998)^{1}$ que crea la Corte Penal Internacional ${ }^{2}$, la 16ta. Asamblea de Estados Partes adoptó, por consenso, la Resolución ICC-ASP/16/Res.53, denominada "Activación de la competencia de la Corte respecto del crimen de agresión". Esta resolución, pese a no haber sido debidamente publicitada por la prensa internacional e incluso en los medios académicos, tiene una gran trascendencia histórica para la humanidad.

En efecto, la aprobación de la Res.5 (2017) precitada, al activar, a partir del 17 de julio de 2018, la competencia de la Corte respecto del crimen de agresión, marca un antes y un después, a nivel universal, respecto del crimen de agresión, por dos razones. ${ }^{\circ}$

En primer lugar, porque en virtud de la Res.5 (2017), ha devenido en aplicable, en el marco del Estatuto de Roma, la definición del crimen de agresión adoptada el año 2010 por la Conferencia de Estados Partes en el Estatuto de Roma, realizada en

\footnotetext{
1 Aprobado en Roma el 17 de julio de 1998 por la Conferencia Diplomática de Plenipotenciarios de las Naciones Unidas (15 de junio a 17 de julio de 1998). Entrada en vigor: 1 ro de julio de 2002. El Perú es Estado parte en este tratado: ratificado mediante el Decreto Supremo 079-2001-RE del 05 de octubre de 2001.

2 La Corte Penal Internacional, en adelante, también, CPI o la Corte, fue creada por el artículo 1 del Estatuto de Roma. Artículo 1. Parte I.- Del establecimiento de la Corte.

"Se instituye por el presente una Corte Penal Internacional («la Corte»). La Corte será una institución permanente, estará facultada para ejercer su jurisdicción sobre personas respecto de los crímenes más graves de trascendencia internacional de conformidad con el presente Estatuto y tendrá carácter complementario de las jurisdicciones penales nacionales. La competencia y el funcionamiento de la Corte se regirán por las disposiciones del presente Estatuto».

3 En adelante, también, Res.5 (2017). Ver texto completo en el portal electrónico de la CPI.
} 
Kampala (Uganda) ${ }^{4}$. La definición adoptada en Kampala era necesaria, toda vez que, la versión original del Estatuto de Roma, no estableció definición alguna sobre dicho crimen. Sin embargo, en Kampala se acordó también que sería necesaria una segunda votación, a realizarse no antes del primero de enero del ańo 2017, para activar la competencia de la Corte respecto del crimen de agresión. Por ello, al quedar firme y operativa, en virtud de la Res.5 (2017), la definición de agresión, además de sus efectos directos en el marco del Estatuto de Roma, se reafirma el alcance universal de la sanción penal de dicho crimen, tal como se sostenía desde los tribunales de Nuremberg (1945-1946) y de Tokio (1946-1948), en virtud, de normas jurídicas internacionales no-convencionales, esto es, consuetudinarias o de jus cogens.

En segundo lugar, porque la Res.5 (2017) otorga competencia efectiva a un órgano jurisdiccional, la Corte Penal Internacional, a fin de que, en el marco del Estatuto de Roma, administre justicia respecto del crimen de agresión, tanto en lo que concierne a los Estados aceptantes de la enmienda, como a nivel universal en ciertos casos.

A continuación, en sendas secciones, el presente trabajo abordará la cuestión de la definición del crimen de agresión en el marco del Estatuto de Roma y su repercusión universal, y luego la cuestión de la competencia de la Corte Penal Internacional sobre dicho crimen.

\section{Una norma jurídica internacional de carácter penal y de alcance universal}

\subsection{Antecedentes: el período entreguerras 1919-1939}

El derecho internacional, antes del tratado de Versalles (1919), admitía que no era posible examinar desde el punto de vista jurídico la cuestión de la guerra legítima. Un ilustre internacionalista de la época, el profesor E. Nys, argumentaba en el sentido que, si bien los autores antiguos distinguían numerosos tipos de guerra, «la ciencia del Derecho Internacional constata el hecho de la guerra» porque «el derecho de hacer la guerra pertenece al Estado, y quien proclama una guerra proclama una acción de soberanía suprema». En otros términos, «el derecho de guerra pertenece al Estado soberano" (Nys, 1906, pp. 101 y 114). Igualmente, en la época, otro internacionalista sostiene: en la medida que «no existe ninguna jurisdicción suprema encargada de aplicar el derecho», la guerra deviene entonces en el instrumento mediante el cual los Estados pueden solucionar sus litigios (Mérignhac, 1912, pp. 10 y 11).

\footnotetext{
4 Se trata de la Conferencia de Revisión de los Estados Partes en el Estatuto de Roma convocada por el secretario general de la ONU, prevista en el artículo 123 del mismo Estatuto; la conferencia se realizó en Kampala (Uganda), del 31 de mayo al 11 de junio de 2010. Véase todo el material relativo a esta conferencia en el portal electrónico de la Corte Penal Internacional, incluida la Resolución 6 relativa al crimen de agresión.
} 
Ninguna persecución penal internacional era posible respecto del crimen de agresión. Las atrocidades de la Primera Guerra Mundial (1914-1919) provocaron un cambio en la posición de muchos juristas y Estados, tal como se aprecia en las negociaciones y en el texto del Tratado de Versalles (1919) que puso fin a dicha guerra. Los juristas integrantes de la Comisión de los Quince, creada por la Conferencia de preliminares de la Paz a fin de investigar las responsabilidades en relación con la guerra, reconoció el problema en que se hallaban:

[...] la premeditación de una guerra de agresión [...] es un acto que la conciencia pública reprueba y que la historia condena, empero, en razón del carácter puramente facultativo de las instituciones creadas en La Haya [Conferencias de la Paz de 1901 y de 1907, respectivamente] tales como la Comisión internacional de investigación, de mediación o de arbitraje, una guerra de agresión no puede ser considerada como un acto rigurosamente contrario al derecho [internacional] positivo, no existiendo posibilidad de crear un tribunal como aquel que la Comisión está autorizada a proponer de acuerdo con los términos de su mandato (Comisión de los Quince, 1919, pp. 51-52). ${ }^{5}$

En consecuencia, concluye la Comisión, «[...] ninguna persecución de carácter criminal puede iniciarse contra los autoridades o individuos responsables y especialmente contra el ex-Kaiser [Guillermo II, ex-Emperador de Alemania]». Y recomienda: «sería deseable que en adelantes sean previstas sanciones penales internacionales para los casos de violación graves de los principios más elementales del Derecho Internacional» (Comisión de los Quince, 1919, p. 53).

Pese a la constatación anterior y a la oposición de la representación estadounidense, los Estados europeos decidieron aprobar un artículo destinado a crear un Tribunal internacional especial a fin de juzgar al ex emperador. ${ }^{6} \mathrm{El}$ juicio nunca se llevó a cabo toda vez que los Países Bajos rechazaron el pedido de entrega del ex emperador, refugiado en su territorio, formulado por los Estados vencedores de la guerra. Sin embargo, lo plasmado en el artículo 227 del Tratado de Versalles refleja bien el cambio radical que se había producido en el Derecho Internacional: de ser un derecho

\footnotetext{
5 Rapport présenté à la conférence des préliminaires de la paix de 1919 par la Commission des responsabilités des auteurs de la guerre et sanctions.

6 Tratado de Versalles: «PARTE VII.- SANCIONES. ARTICULO 227. Los Aliados y Potencias Asociadas públicamente acusan a William II de Hohenzollern, formalmente Emperador de Alemania, por una suprema ofensa contra la moral internacional y la inviolabilidad de los tratados.

Un Tribunal Especial será constituido para la acusación, asegurándole las garantías esenciales del derecho de defensa. El Tribunal estará compuesto de cinco jueces, cada uno designado por cada una de las siguientes potencias: Estados Unidos de América, Gran Bretaña, Francia, Italia y Japón.

En su decisión el Tribunal será guiado por los altos motivos de la política internacional, tomando en cuenta las solemnes obligaciones de las garantías internacionales y la validez internacional de la moral. Será su deber señalar el castigo que considere deber ser impuesto.

Los Aliados y Potencias Asociadas enviaran una solicitud al Gobierno de Holanda para que les entregue al Ex Emperador a fin de que sea juzgado.»
} 
de los Estados, la guerra devino en la «suprema ofensa contra la moral internacional y la inviolabilidad de los tratados ${ }^{7}$. Y, conforme a lo expresado por la Comisión de los Quince, reseñada supra, en los años que siguieron, la comunidad internacional se esmeró en calificar la guerra de agresión no solo como un acto prohibido sino como un crimen de Derecho Internacional.

Luego del Tratado de Versalles, la comunidad internacional se fue posicionando en el sentido que la guerra de agresión era un acto ilícito y un crimen internacional. Así, podemos mencionar:

a. El proyecto de tratado de asistencia recíproca, elaborado bajo los auspicios de la Sociedad de las Naciones en 1923: «la guerra de agresión es un crimen internacional» (artículo primero).

b. El protocolo de Ginebra de 1924 para la solución pacífica de los diferendos internacionales: «una guerra de agresión constituye [...] un crimen internacional» ( preámbulo).

c. La resolución adoptada unánimemente por la Asamblea de la Sociedad de las Naciones el 24 de setiembre de 1927: «la guerra de agresión constituye un crimen internacional contra el género humano» (preámbulo).

d. La resolución adoptada unánimemente por la sexta Conferencia Panamericana el 18 de febrero de 1928: «la guerra de agresión constituye un crimen internacional contra el género humano».

e. El pacto Briand-Kellogg del 27 de agosto de1928. Este pacto, en vigor desde el 29 de julio de 1929 y conocido por los nombres de los cancilleres de Francia y de Estados Unidos, respectivamente, quienes lo promovieron, declara que los Estados partes «condenan recurrir a la guerra en búsqueda de la solución de controversias internacionales y además, renuncian a ella, como instrumento de política nacional en sus relaciones con otros Estados». Este tratado, con sesenta y tres Estados partes, tiene particular relevancia porque entre los Estados que lo ratificaron o adhirieron se incluye Alemania, Italia y Japón (ONU, 1949, p. 47; Tribunal de Núremberg, 1947 , t. XXII, pp. 492-495). ${ }^{8}$

\footnotetext{
7 Además de lo establecido por el Tratado de Versalles en la Parte VII relativa a sanciones penales aplicables a los responsables de la guerra y de crímenes de guerra, el mismo tratado creó la Liga o Sociedad de la Naciones (artículos 1 a 26) y estableció en los artículos 10 y 11 cláusulas cuyo objeto era preservar la paz y apoyar a los Estados miembros que fueran víctimas de actos de agresión. Lamentablemente, estas cláusulas no fueron activadas cuando Hitler desató la Segunda Guerra Mundial (1939-1945).

8 Para el desarrollo de esta sección nos hemos servido de lo avanzado sobre este tema en nuestro libro Derecho Penal Internacional. Genealogía de los crimenes internacionales más graves (pp. 345-346). Lima, Fondo Editorial PUCP, 2017.
} 
En conclusión, antes del inicio de la Segunda Guerra Mundial, en el período entre guerras (1919-1939), los instrumentos internacionales precitados evidencian que una nueva una nueva concepción jurídica se había desarrollado y cristalizado en Derecho Internacional respecto de la guerra de agresión. En estos mismos años, la academia estuvo muy activa y concluyó declarando mediante las principales asociaciones jurídicas internacionales existentes, que la guerra de agresión es un crimen internacional ${ }^{9}$.

\subsection{La sanción penal del crimen de agresión en el período 1945-1998.}

Concluida la Segunda Guerra Mundial (1939-1945), la cuestión de la sanción penal del crimen de agresión, de los crímenes de guerra y de lesa humanidad, perpetrados por los nazis y sus colaboradores, se planteó no solo a los Aliados sino a la Comunidad internacional en el marco de la naciente Organización de las Naciones Unidas $^{10}$. Si bien la sanción penal del crimen de agresión se estableció expresamente mediante el Derecho de Núremberg ${ }^{11}$, es necesario tener presente que la Carta de la ONU reafirma y perfecciona las normas jurídicas que sobre la guerra de agresión se desarrollaron en el período entreguerras analizado supra. Así, la Carta de las Naciones Unidas, tratado adoptado en San Francisco el 26 de junio de 1945, proclama como uno de sus fines la defensa efectiva de la paz (artículo 1.1), prohíbe la amenaza o el uso de la fuerza entre todos los Estados (artículo 2.4), salvo la legítima

\footnotetext{
9 La International Law Association abordó esta temática en su sesión de Buenos Aires (1922) y en su sesión de Estocolmo (1924); luego, sobre la base del proyecto elaborado por el profesor de la Universidad de Londres, H. H. Bell, aprobó un proyecto de estatuto de Corte Penal Internacional Permanente en su sesión de Viena (1926). (International Law Association, 1925, pp. 81 y 96; 1927, p. 135). Por su parte, la Unión Interparlamentaria Mundial examinó el proyecto elaborado, a pedido de ella, por el jurista rumano V. Pella, durante su sesión de Washington (Pella, 1925). Finalmente, merece destacarse la labor de la Association Internationale de Droit Pénal, creada en la ciudad de París en marzo de 1924 y presidida por el jurista belga conde Carton de Wiart. La asociación se pronunció (en su primer congreso tenido en Bruxelles el ańo 1926) igualmente por la creación de una Corte Penal Internacional permanente como parte de la ya existente Corte Permanente de Justicia Internacional, cuya competencia debiera comprender delitos imputables al Estados, destacando entre tales delitos la guerra de agresión, de una parte, y de otra parte, delitos imputables a los individuos, inter alia, vinculados al «crimen de agresión» (Revue Internationale de Droit Pénal, 1926, p. 462).

10 La Carta de las Naciones Unidas se aprobó en San Francisco el 26 de junio de 1945 y entró en vigor el 24 de octubre del mismo año.

11 El tratado fundacional del Derecho de Núremberg es el Acuerdo de Londres y su Anexo el Estatuto del Tribunal Internacional de Núremberg, aprobados el 8 de agosto de 1945. El Tribunal Internacional de Núremberg era competente, ratione personae, para el juzgamiento de los principales responsables nazis y colaboradores, del crimen de agresión, crímenes de guerra y lesa humanidad. Luego del juzgamiento correspondiente, el Tribunal pronunció sentencia en septiembre del ańo siguiente. El tratado fue aprobado por los Estados Unidos, Inglaterra, Francia y la ex-URSS, adhiriendo luego otros Estados. En enero de 1946 fue creado el Tribunal de Tokio con un mandato similar al Tribunal de Núremberg, pero limitado en este caso, ratione personae, a los más altos mandos militares y políticos del Imperio Japonés; este tribunal expidió sentencia en diciembre de 1948. En lo que se refiere al crimen de agresión, el texto de tribunal de Tokio es idéntico al texto del Tribunal de Núremberg, precisándose empero que la guerra puede ser declarada o no declarada.
} 
defensa (artículo 51) y encarga al Consejo de Seguridad que adopte medidas eficaces al respecto, incluso la guerra contra el Estado agresor (Capítulo VII, artículos 39 a 51) en defensa de la paz. Esta posición que hallamos en la Carta de la ONU consolida el proceso iniciado en el período entreguerras 1919-1939: la guerra de agresión constituye una violación grave e inaceptable en Derecho Internacional.

Terminada la Segunda Guerra Mundial (1939-1945), la Comunidad Internacional tenía ahora sí, a diferencia de lo sucedido al término de la primera (1914-1919), los instrumentos jurídicos internacionales necesarios para sancionar penalmente el crimen de agresión. El Estatuto del Tribunal de Nuremberg estableció entonces:

Artículo 6. El Tribunal establecido por el Acuerdo referido en el artículo 1 del presente documento para el juicio y castigo de los mayores criminales de guerra de los países del Eje Europeo tendrá el poder de jugar y castigar personas que, actuando en pro de los intereses de los países del Eje Europeo, ya sea como individuos o como miembros de organizaciones, cometieron algunos de los siguientes crímenes.

Los siguientes actos, o cualquiera de ellos, son crímenes comprendidos en la jurisdicción del Tribunal por los que habrá responsabilidad individual:

a) Crímenes contra la paz: a saber, planeamiento, preparación, iniciación o desarrollo de una guerra de agresión, o una guerra en violación de tratados internacionales, acuerdos o garantías, o participación en un plan común o conspiración para el logro de cualquiera de actos los mencionados (traducción no oficial).

b) Crímenes de guerra (...)

c) Crímenes contra la humanidad.

Como se aprecia en el texto citado, la competencia personal del Tribunal está limitada a los más altos responsables nazis de la guerra en Europa, incluidos sus colaboradores, e incrimina como crimen contra la paz, dos tipos de actos relativos todos a la guerra de agresión o una guerra en violación de acuerdos internacionales en general. El primer tipo de actos se refiere al proceso de realización de la guerra (planeamiento, preparación, iniciación, desarrollo), el segundo tipo de actos se refiere a la participación en un plan común o conspiración para perpetrar cualquiera de los actos antes mencionados. El Tribunal de Núremberg, finalmente, en su sentencia emitida el 30 de septiembre y el 1 ro de octubre de $1946^{12}$, declaró:

Realizar una guerra de agresión no es solamente un crimen internacional: es el crimen internacional supremo, no diferenciándose de los otros crímenes de guerra sino en el hecho que les contiene a todos (Tribunal de Núremberg, 1947, t. I, p. 187; énfasis nuestro).

\footnotetext{
12 El Tribunal de Nuremberg juzgó a 22 (veinte y dos) acusados, de los cuales tres fueron liberados, y respecto de los otros 19, fueron 12 condenados a muerte y 7 a penas de prisión.
} 
Luego del juicio de Núremberg, así como de los juicios llevados a cabo por el Tribunal de Tokio y por los tribunales militares de ocupación en Alemania ${ }^{13}$ contra los nazis y sus colaboradores, la comunidad internacional una y otra vez reiteró su apoyo al Derecho de Núremberg así como su alcance universal y no circunscrito a los vencidos de la Segunda Guerra Mundial. En este sentido podemos mencionar diversos instrumentos internacionales entre los que destacan:

- la Convención para la represión del crimen de genocidio (1948),

- la Convención sobre la imprescriptibilidad de los crímenes de guerra y de lesa humanidad (1969),

- la Resolución 2625 (XXV) adoptada por la Asamblea General de las Naciones Unidas el 24 de octubre de 1970, denominada «Declaración sobre los principios de Derecho Internacional referentes a las relaciones de amistad y cooperación entre los Estados de conformidad con la Carta de las Naciones Unidas",

- la Resolución 3074 (XXVIII) adoptada por la Asamblea General de las Naciones Unidas el 3 de diciembre de 1973, denominada «Principios de cooperación internacional en la identificación, detención, extradición y castigo de los culpables de crímenes de guerra y de lesa humanidad», $y$

- la Resolución 3314 (XXIX) adoptada por la Asamblea General de las Naciones Unidas el 14 de diciembre de 1974, denominada «Definición de la agresión»" ${ }^{14}$.

Además de los instrumentos mencionados supra, es necesario tener en consideración que, la Corte Internacional de Justicia, se pronunció reiteradamente en el sentido que la prohibición de la agresión era una obligación de alcance universal, erga omnes, por lo que no dependía de su incorporación en un tratado específico ${ }^{15}$.

13 Los Tribunales de ocupación instalados por los Aliados en Alemania al término de la guerra se rigieron por la Ley No. 10, emitida por el Consejo de Control Aliado en Alemania en diciembre de 1945; esta ley reproduce con algunas modificaciones lo establecido en el Estatuto del Tribunal de Núremberg.

14 La Asamblea General de la ONU mediante su Resolución 95 (I) de fecha 11 de diciembre de 1946, declaró que "confirma los principios de Derecho Internacional reconocidos por el Estatuto del Tribunal de Núremberg y las sentencias de dicho tribunal». Ulteriormente, una comisión de Estados designados por la Asamblea General, elaboró el Primer Proyecto de Estatuto de una Corte Penal Internacional. Sin embargo, decidió la Asamblea que no se crearía la Corte mientras no se lograra una definición consensuada respecto del crimen de agresión. Esta decisión se aplicó igualmente respecto del Primer Proyecto de crímenes contra la Paz y la seguridad de la humanidad, elaborado por la Comisión de Derecho Internacional a pedido de la misma Asamblea General; este proyecto incluía una definición del crimen de agresión. Cf. Resoluciones 897 (I) y 898 (I) adoptadas el 04 y el 14 de diciembre de 1954. Finalmente, la definición de agresión fue aprobada por la Asamblea General mediante la Resolución 3314 (XXIX) el año 1974, pero no se tomó entonces la decisión de crear la Corte Penal Internacional hasta que se aprobó el Estatuto de Roma el año 1998. Como analizaremos a continuación, el Estatuto de Roma mencionado no incluyó una definición del crimen de agresión, en consecuencia, la Corte no podía juzgar ningún caso relacionado con el crimen de agresión.

15 La Corte Internacional de Justicia en su sentencia sobre el caso Barcelona Traction, Light and Power Company, Limited, fallo de 2 de febrero de 1970, declaró: «33. [...] Una distinción esencial debe en particular estar establecida entre las obligaciones de los Estados frente a la comunidad internacional en su conjunto y las que nacen frente a 


\subsection{El crimen de agresión según el Estatuto de Roma que crea la Corte Penal Internacional $^{16}$}

Mediante el artículo 5 (original), el Estatuto de Roma (1998) estableció —en su numeral 1 - que la Corte Penal Internacional tendrá competencia respecto de los crímenes más graves para la comunidad internacional en su conjunto, entre los cuales se incluyó expresamente el crimen de agresión. Sin embargo, el mismo artículo estableció - en su numeral 2- que, en relación al crimen de agresión, la competencia de la Corte quedaba en suspenso hasta que se aprobara — de conformidad con los artículos 121 y 123 - una disposición mediante la cual se defina dicho crimen internacional y se enuncie las condiciones en las cuales la Corte ejercerá su competencia respecto de este crimen. Finalmente, el artículo 5.2 precisó también que la disposición por aprobarse deberá ser compatible con las disposiciones pertinentes de la Carta de las Naciones Unidas ${ }^{17}$. Los artículos 121 y 123, antes mencionados, regulan todo lo concerniente a la adopción de enmiendas al Estatuto de Roma ${ }^{18}$.

otro Estado dentro del marco de la protección diplomática. Por su naturaleza misma, las primeras atañen a todos los Estados. Dada la importancia de los derechos en causa, todos los Estado pueden considerar que tienen un interés jurídico de que estos derechos sean protegidos, se trata de obligaciones «erga omnes». 34. Estas obligaciones derivan por ejemplo, en el derecho internacional contemporáneo, de la puesta al margen de la ley de actos de agresión y del genocidio pero también de los principios y reglas que atañen a los derechos fundamentales de la persona humana, incluido la protección contra la práctica de la esclavitud y la discriminación racial. Ciertos derechos de protección correspondientes se han integrado al derecho internacional general (Reservas a la convención sobre la prevención y represión del crimen de genocidio, opinión consultiva, CIJ, 1951, p.23); otras están otorgadas por instrumentos internacionales de carácter universal o casi universal».

16 En la medida que la Res. 5 (2017) no modifica la definición del crimen de agresión adoptada en Kampala el año 2010, sigue siendo válido el análisis que al respecto se encuentra en nuestro libro publicado en octubre de 2017 (Burneo, 2017, pp. 319-333). Por ello, para mantener la coherencia interna del presente artículo, la sección C que a continuación presentamos, con algunos cambios, reproduce lo analizado en el libro mencionado.

17 El artículo 5 se lee como sigue:

«Crímenes de la competencia de la Corte.

1. La competencia de la Corte se limitará a los crímenes más graves de trascendencia para la comunidad internacional en su conjunto. La Corte tendrá competencia, de conformidad con el presente Estatuto, respecto de los siguientes crímenes:

a) El crimen de genocidio;

b) Los crímenes de lesa humanidad;

c) Los crímenes de guerra;

d) El crimen de agresión.

2. La Corte ejercerá competencia respecto del crimen de agresión una vez que se apruebe una disposición de conformidad con los artículos 121 y 123 en que se defina el crimen y se enuncien las condiciones en las cuales lo hará. Esa disposición será compatible con las disposiciones pertinentes de la Carta de las Naciones Unidas.»

18 El Estatuto de Roma, en sus artículos 121 y 123, establece, entre otros aspectos, que la propuesta de enmiendas y la realización de conferencias de revisión del Estatuto de Roma, respectivamente, podrán efectuarse siete años después de su entrada en vigor. Habiendo entrado en vigor el Estatuto con fecha 1 de julio de 2002, de conformidad con su artículo 126, los siete años se cumplieron en julio del ańo 2009. Luego de la primera conferencia de revisión, las enmiendas pueden ser vistas para su eventual aprobación sea en una sesión de la Asamblea General de los Estados partes en el Estatuto de Roma o mediante una nueva conferencia de revisión (artículo 121, numerales 2 y 3; y artículo 123, numeral 2); en cualquiera de las dos modalidades se requerirá la aprobación de la enmienda en cuestión 
La "Primera conferencia de revisión de los Estados partes en el Estatuto de Roma» adoptó, en relación al crimen de agresión, diversas enmiendas al mencionado estatuto, así como a los elementos de los crímenes. Estas enmiendas se encuentran contenidas en la resolución RC/Res.6 sobre el crimen de agresión (del 11 de junio de 2010), aprobada por consenso luego de intensas negociaciones en la decimotercera sesión plenaria el último día de la conferencia ${ }^{19}$. La resolución adoptó los cinco acuerdos siguientes:

1. Decide aprobar, de conformidad con el párrafo 2 del artículo 5 del Estatuto de Roma de la Corte Penal Internacional (en adelante el «Estatuto»), las enmiendas del Estatuto que figuran en el anexo I de la presente resolución, que estarán sujetas a ratificación o aceptación y entrarán en vigor de conformidad con lo dispuesto en el párrafo 5 del artículo 121 del Estatuto; y señala que cualquier Estado Parte podrá depositar una declaración como establece el artículo 15 bis antes de la ratificación o aceptación;

2. Decide además aprobar las enmiendas a los elementos de los crímenes que figuran en el anexo II de la presente resolución;

3. Decide además aprobar los entendimientos respecto de la interpretación de las enmiendas mencionadas, contenidos en el anexo III de la presente resolución;

4. Decide asimismo revisar las enmiendas relativas al crimen de agresión siete años después del inicio del ejercicio de la competencia de la Corte;

5. Exhorta a todos los Estados Partes a que ratifiquen o acepten las enmiendas contenidas en el anexo I.

En cuanto a las enmiendas al Estatuto de Roma y relativas al crimen de agresión, en el anexo I de la resolución precitada se acuerdan siete enmiendas:

Anexo I. Enmiendas al Estatuto de Roma de la Corte Penal Internacional relativas al crimen de agresión.

1. Suprímase el párrafo 2 del artículo 5 del Estatuto.

2. Insértese el texto siguiente a continuación del artículo 8 del Estatuto:

Artículo 8 bis Crimen de agresión [...].

3. Insértese el texto siguiente a continuación del artículo 15 del Estatuto:

Artículo 15 bis Ejercicio de la competencia respecto del crimen de agresión (remisión por un Estado, proprio motu). [...]

por los dos tercios de los Estados partes. Las enmiendas aprobadas vía Asamblea General o vía conferencia de revisión obligan únicamente a los Estados partes en el Estatuto de Roma que depositen los instrumentos de ratificación o de adhesión correspondientes (arts. 121, numeral 5, y 123, numeral 3).

19 La versión completa de la resolución RC/Res.6 sobre el crimen de agresión se encuentra disponible en el portal electrónico de la Corte Penal Internacional. 
4. Insértese el texto siguiente a continuación del artículo 15 bis del Estatuto:

Artículo 15 ter Ejercicio de la competencia respecto del crimen de agresión (remisión por el Consejo de Seguridad).[...]

5. Insértese el texto siguiente a continuación del párrafo 3 del artículo 25 del Estatuto:

3bis. Por lo que respecta al crimen de agresión, las disposiciones del presente artículo solo se aplicarán a las personas en condiciones de controlar o dirigir efectivamente la acción política o militar de un Estado.

6. Sustitúyase la primera oración del párrafo 1 del artículo 9 del Estatuto por la oración siguiente:

1. Los Elementos de los crímenes ayudarán a la Corte a interpretar y aplicar los artículos 6, 7, 8 y 8 bis.

7. Sustitúyase el encabezamiento del párrafo 3 del artículo 20 del Estatuto por el párrafo siguiente; el resto del párrafo no se modifica:

3. La Corte no procesará a nadie que haya sido procesado por otro tribunal en razón de hechos también prohibidos en virtud de los artículos $6,7,8$ u 8 bis a menos que el proceso en el otro tribunal.

El anexo II de la resolución precitada añade, en los Elementos de los crímenes, una nueva sección relativa al crimen de agresión. De esta manera, la conferencia de revisión cumplió con lo exigido por el derogado artículo 5.2; esto es, acompañar la definición del crimen de agresión (artículo 8 bis) de las condiciones en que la Corte Penal Internacional ejercerá su competencia (artículos 15 bis y 15 ter) respecto de dicho crimen. En los artículos 15 bis y 15 ter es donde se decreta dejar en suspenso la definición aprobada hasta que, entre otros requisitos, se proceda a una nueva votación, la cual deberá tener lugar a partir del 1 de enero de 2017. El anexo I, además, introduce enmiendas vinculadas al crimen de agresión que afectan los siguientes tres artículos del Estatuto de Roma: artículo 25 sobre responsabilidad penal individual ${ }^{20}$; artículo 9 sobre los elementos de los crímenes ${ }^{21}$ y artículo 20 sobre cosa juzgada ${ }^{22}$.

20 La enmienda relativa al artículo 25 dice: «Insértese el texto siguiente a continuación del párrafo 3 del artículo 25 del Estatuto: 3 bis. Por lo que respecta al crimen de agresión, las disposiciones del presente artículo solo se aplicarán a las personas en condiciones de controlar o dirigir efectivamente la acción política o militar de un Estado».

21 La enmienda relativa al artículo 9 dice: «Sustitúyase la primera oración del párrafo 1 del artículo 9 del Estatuto por la oración siguiente: 1. Los Elementos de los Crímenes ayudarán a la Corte a interpretar y aplicar los artículos 6, 7, 8 y 8 bis».

22 La enmienda relativa al artículo 20 dice: «Sustitúyase el encabezamiento del párrafo 3 del artículo 20 del Estatuto por el párrafo siguiente; el resto del párrafo no se modificó: 3. La Corte no procesará a nadie que haya sido procesado por otro tribunal en razón de hechos también prohibidos en virtud de los artículos $6,7,8$ u 8 bis a menos que el proceso en el otro tribunal». 
La definición del crimen de agresión, aprobada en Kampala y contenida en el artículo 8 bis, remite expresamente, en cuanto a los elementos materiales del crimen de agresión, a los actos establecidos al respecto por la Asamblea General de las Naciones Unidas en su resolución 3314 (XXI), adoptada por consenso el 14 de diciembre de 1974. Se lee así en el artículo 8 bis:

Artículo 8 bis

Crimen de agresión

1. A los efectos del presente Estatuto, una persona comete un «crimen de agresión» cuando, estando en condiciones de controlar o dirigir efectivamente la acción política o militar de un Estado, dicha persona planifica, prepara, inicia o realiza un acto de agresión que por sus características, gravedad y escala constituya una violación manifiesta de la Carta de las Naciones Unidas.

2. A los efectos del párrafo 1, por «acto de agresión» se entenderá el uso de la fuerza armada por un Estado contra la soberanía, la integridad territorial o la independencia política de otro Estado, o en cualquier otra forma incompatible con la Carta de las Naciones Unidas. De conformidad con la resolución 3314 (XXIX) de la Asamblea General de las Naciones Unidas, de 14 de diciembre de 1974, cualquiera de los actos siguientes, independientemente de que haya o no declaración de guerra, se caracterizará como acto de agresión [...].

Luego, se transcriben literalmente, sin cambiar una coma, todos los actos de agresión (siete en total) establecidos en 1974: literales $a$ hasta el literal $g$ inclusive ${ }^{23}$, El artículo

23 El artículo 8 bis se lee como sigue: «Artículo 8 bis. Crimen de agresión

1. A los efectos del presente Estatuto, una persona comete un «crimen de agresión» cuando, estando en condiciones de controlar o dirigir efectivamente la acción política o militar de un Estado, dicha persona planifica, prepara, inicia o realiza un acto de agresión que por sus características, gravedad y escala constituya una violación manifiesta de la Carta de las Naciones Unidas.

2. A los efectos del párrafo 1, por «acto de agresión» se entenderá el uso de la fuerza armada por un Estado contra la soberanía, la integridad territorial o la independencia política de otro Estado, o en cualquier otra forma incompatible con la Carta de las Naciones Unidas. De conformidad con la resolución 3314 (XXIX) de la Asamblea General de las Naciones Unidas, de 14 de diciembre de 1974, cualquiera de los actos siguientes, independientemente de que haya o no declaración de guerra, se caracterizará como acto de agresión:

a) La invasión o el ataque por las fuerzas armadas de un Estado del territorio de otro Estado, o toda ocupación militar, aún temporal, que resulte de dicha invasión o ataque, o toda anexión, mediante el uso de la fuerza, del territorio de otro Estado o de parte de él;

b) El bombardeo, por las fuerzas armadas de un Estado, del territorio de otro Estado, o el empleo de cualesquiera armas por un Estado contra el territorio de otro Estado;

c) El bloqueo de los puertos o de las costas de un Estado por las fuerzas armadas de otro Estado;

d) El ataque por las fuerzas armadas de un Estado contra las fuerzas armadas terrestres, navales o aéreas de otro Estado, o contra su flota mercante o aérea;

e) La utilización de fuerzas armadas de un Estado, que se encuentran en el territorio de otro Estado con el acuerdo del Estado receptor, en violación de las condiciones establecidas en el acuerdo o toda prolongación de su presencia en dicho territorio después de terminado el acuerdo;

f) La acción de un Estado que permite que su territorio, que ha puesto a disposición de otro Estado, sea utilizado por ese otro Estado para perpetrar un acto de agresión contra un tercer Estado; 
8 bis contiene, sin embargo, un numeral cuyo contenido no se encuentra en la resolución 3314 precitada. Se trata del numeral relativo al sujeto perpetrador del crimen de agresión (ver numeral 1 del artículo 8 bis), toda vez que, en la resolución 3314, dado que sus objetivos no eran la sanción penal de las personas naturales, no se precisaron las características del sujeto perpetrador.

Es de relievar, finalmente, el hecho que el artículo 8 bis fue aprobado tal cual fuera propuesto por el grupo de trabajo especial preparatorio de la primera conferencia de revisión (documento ICC-ASP/8/20)24.

Para establecer los elementos del crimen de agresión, es necesario tener en consideración el artículo 8 bis del Estatuto de Roma, y, complementariamente, el texto correspondiente de los Elementos de los crímenes, texto que fue también aprobado en la primera conferencia de revisión como anexo $\mathrm{II}^{25}$.

g) El envío por un Estado, o en su nombre, de bandas armadas, grupos irregulares o mercenarios que lleven a cabo actos de fuerza armada contra otro Estado de tal gravedad que sean equiparables a los actos antes enumerados, o su sustancial participación en dichos actos.»

24 El texto fue publicado durante el trabajo preparatorio de la conferencia de Kampala como C.N.727.2009. TREATIES-7, del 29 de octubre de 2009.

25 Mediante la resolución RC/Res.6 (numeral 2), precitada, la primera conferencia de revisión «[d]ecide además aprobar las enmiendas a los elementos de los crímenes que figuran en el anexo II de la presente resolución». Este anexo se lee como sigue:

«Anexo II Enmiendas a los Elementos de los crímenes.

Artículo 8 bis Crimen de agresión

Introducción

1. Se entenderá que cualquiera de los actos a los que se hace referencia en el párrafo 2 del artículo 8 bis se caracteriza como un acto de agresión.

2. No existe obligación de demostrar que el autor haya llevado a cabo una evaluación en derecho de la incompatibilidad del uso de la fuerza armada con la Carta de las Naciones Unidas.

3. La expresión «manifiesta» es una calificación objetiva.

4. No existe la obligación de demostrar que el autor haya llevado a cabo una evaluación en derecho de la naturaleza «manifiesta» de la violación de la Carta de las Naciones Unidas.

Elementos

1. Que el autor haya planificado, preparado, iniciado o realizado un acto de agresión.

2. Que el autor sea una personal que estaba en condiciones de controlar o dirigir efectivamente la acción política o militar del Estado que cometió el acto de agresión.

3. Que el acto de agresión - el uso de la fuerza armada por un Estado contra la soberanía, la integridad territorial o la independencia política de otro Estado, o en cualquier otra forma incompatible con la Carta de las Naciones Unidas - se haya cometido.

4. Que el autor haya tenido conocimiento de las circunstancias de hecho que determinaban la incompatibilidad de dicho uso de la fuerza armada con la Carta de las Naciones Unidas.

5. Que el acto de agresión, por sus características, gravedad y escala, haya constituido una violación manifiesta de la Carta de las Naciones Unidas.

6. Que el autor haya tenido conocimiento de las circunstancias de hecho que constituían dicha violación manifiesta de la Carta de las Naciones Unidas.

Nota 1. Respecto de un acto de agresión, puede suceder que más de una persona se halle en una situación que cumpla con estos criterios. 
De acuerdo con el artículo 8 bis del Estatuto de Roma, en cuanto al autor, se trata de toda persona que, «estando en condiciones de controlar o dirigir efectivamente la acción política o militar de un Estado, dicha persona planifica, prepara, inicia o realiza un acto de agresión» que "constituya una violación manifiesta de la Carta de las Naciones Unidas» (artículo 8 bis, numeral 1).

En este orden de ideas, el autor no es el soldado o funcionario que obedece órdenes y está en un papel subordinado; sino alguien que se ubica en la escala más alta del poder en un Estado y que, por ello, está en condiciones de controlar o dirigir efectivamente la acción política o militar de dicho Estado. Esta calidad de autor es reiterada en el anexo I, numeral 5, en los siguientes términos:

5. Insértese el texto siguiente a continuación del párrafo 3 del artículo 25 [sobre «Responsabilidad penal individual»] del Estatuto:

3 bis. Por lo que respecta al crimen de agresión, las disposiciones del presente artículo solo se aplicarán a las personas en condiciones de controlar o dirigir efectivamente la acción política o militar de un Estado.

Esta limitación de la responsabilidad e imputabilidad penal del crimen de agresión a gobernantes y principales autoridades del Estado tiene su precedente en los juicios de Nuremberg y de Tokio contra los principales responsables de la Segunda Guerra Mundial ${ }^{26}$.

Por su parte, la Comisión de Derecho Internacional, en su proyecto de código de crímenes contra la paz y la seguridad de la humanidad, adoptado en su versión definitiva el año 1996, restringió igualmente la calidad de autor al individuo que actúa en calidad de dirigente o de organizador y, de esta forma, toma parte activa u ordena la planificación, la preparación, el inicio o la conducción de una agresión (artículo 16) (David, 2009, párr. 15.2.13 a 15.2.15, pp. 1087 a 1091; Salmón y Bazay, 2011, pp. 24 y 35 a 44).

En cuanto a los actos de agresión, son siete sus tipos que, como elementos materiales, concurren en la construcción del tipo penal (Salmón y Bazay, 2011, pp. 44-53).

\footnotetext{
26 En el Estatuto del Tribunal Internacional de Núremberg, se restringe la calidad de autor a los principales responsables en los términos siguientes: «Artículo 6. El Tribunal establecido por el Acuerdo [de Londres de 8 de agosto de 1945] para el enjuiciamiento y castigo de los principales criminales de guerra de los países del Eje Europeo tendrá la facultad de enjuiciar y castigar [...]: a) Crímenes contra la paz: a saber, la planificación, la preparación, el inicio o la conducción de una guerra de agresión, o una guerra en violación de los tratados, acuerdos o garantías internacionales, o la participación en un plan común o conspiración para la consecución de cualquiera de los mencionados» (subrayado nuestro, traducción no oficial). En el Estatuto del Tribunal de Tokio de 19 de enero de 1946, luego de precisar en su artículo primero que el tribunal «queda establecido mediante el presente documento para el enjuiciamiento y castigo pronto y justo de los principales criminales de guerra en el Lejano Oriente», reproduce en su artículo 5 a el mismo texto del Estatuto del Tribunal de Núremberg sobre el crimen contra la paz, con la precisión de que la guerra de agresión en cuestión puede ser declarada o no declarada. Véase ambos textos en: Blassi, Reyes y León Vega, 2008, pp. 613 y ss.; y 629 y ss.
} 
Los cinco primeros tipos de actos de agresión — literales $a$ hasta $e$ inclusive— suponen el uso de la fuerza armada de un Estado contra otro. El Estado víctima ve así afectado: $i)$ su territorio, el cual es invadido, objeto de ataque, ocupación, anexión total o parcial, bloqueo de puertos o costas; ii) sus fuerzas armadas; y iii) su flota mercante o aérea. El acto de agresión sexto (literal $f$ ) no supone el uso de la fuerza armada por el Estado en cuestión; sino una decisión política que permite a otro Estado realizar actos de agresión contra un tercer Estado. El acto de agresión último de nuestra lista (el séptimo, literal $g$ ) tampoco supone el uso de la fuerza armada por el Estado en cuestión; sino una decisión política en virtud de la cual dicho Estado envía «bandas armadas, grupos irregulares o mercenarios» que, de acuerdo con el literal mencionado, llevan al cabo actos armados o participan en la realización de tales, contra otro Estado.

Nótese que, según el artículo 8 bis, los actos de agresión en ningún caso suponen necesariamente la existencia de un conflicto armado o de una guerra declarada; tampoco suponen necesariamente que se produzca pérdidas de vidas humanas, daños personales en general, ni daños a la propiedad pública o privada en el territorio del Estado víctima. No se trata por ello necesariamente de una guerra de agresión, sino de actos de agresión que eventualmente pueden constituir un conflicto armado o una guerra de agresión. Será necesario analizar cada caso para determinar si los actos de agresión constituyen una guerra de agresión y si han dado lugar a daños personales o materiales. En todo caso, lo que se penaliza son los actos de agresión tal como se definen en el artículo 8 bis del Estatuto de Roma. Lo que está fuera de dudas es que ciertamente toda guerra de agresión implica la comisión de uno o varios de los actos incriminados; por lo que, si bien no se afirma expresamente, la guerra de agresión constituye un crimen internacional sancionada penalmente al realizar uno o varios de los actos incriminados por el Estatuto de Roma.

En cuanto al umbral de los actos de agresión, es necesario que constituyan una violación manifiesta de la Carta de la ONU. La expresión «violación manifiesta» la encontramos al inicio mismo del artículo 8 bis en los términos siguientes:

Artículo 8 bis. Crimen de agresión

1. A los efectos del presente Estatuto, una persona comete un "crimen de agresión» cuando, estando en condiciones de controlar o dirigir efectivamente la acción política o militar de un Estado, dicha persona planifica, prepara, inicia o realiza un acto de agresión que por sus características, gravedad y escala constituya una violación manifesta de la Carta de las Naciones Unidas (subrayado nuestro).

Sobre el carácter y contenido de la expresión «violación manifiesta», leemos, además, en el anexo II: «[l]a expresión "manifiesta» es una calificación objetiva» (numeral 3 de la introducción); es decir, «el acto de agresión, por sus características, gravedad 
y escala» constituye "una violación manifiesta de la Carta de las Naciones Unidas» (numeral 5 de la sección «elementos»).

En síntesis. A tenor del artículo 8.1 bis y textos complementarios adoptados todos en Kampala, no es suficiente la realización de alguno de los actos incriminados para que, desde el punto de vista material, se impute la comisión de un crimen de agresión a los efectos del Estatuto de Roma. El acto de agresión debe constituir, además, «una violación manifiesta de la Carta de las Naciones Unidas». Ahora bien, para que un acto de agresión pueda calificarse como "violación manifiesta», deberán analizarse tres factores o aspectos en dicho acto; esto es, «sus características, gravedad y escala». En otros términos, si un acto de agresión incluido en la lista no puede ser calificado como "violación manifiesta...», no podrá imputarse a una persona natural, desde el punto de vista objetivo o material, la comisión de un «crimen de agresión» a los efectos del Estatuto de Roma. Esto por cuanto, según los elementos de los crímenes (anexo II, numeral 3, precitado), se trata de una calificación objetiva, constitutiva del tipo penal «crimen de agresión». A mayor abundamiento, en las disposiciones del anexo III («entendimientos sobre las enmiendas...»), aprobadas por la misma resolución $\mathrm{RC} /$ Res.6, podemos también leer:

6. Se entiende que la agresión es la forma más grave y peligrosa del uso ilegal de la fuerza, y que una determinación sobre si un acto de agresión ha sido cometido requiere el examen de todas las circunstancias de cada caso particular, incluyendo la gravedad de los actos correspondientes y de sus consecuencias, de conformidad con la Carta de las Naciones Unidas (subrayado nuestro).

7. Se entiende que al determinar si un acto de agresión constituye o no una violación manifiesta de la Carta de las Naciones Unidas, los tres elementos de características, gravedad y escala deben tener la importancia suficiente para justificar una determinación de violación «manifiesta». Ninguno de los elementos puede bastar por sí solo para satisfacer el criterio de violación manifiesta (subrayado nuestro).

De este modo, en los numerales 6 y 7 del anexo III, se explicita una vez más que, para determinar la existencia de una «violación manifiesta» se deberá considerar tres aspectos concurrentes: características, gravedad y escala del acto de agresión en cuestión. Estos tres aspectos deben tener la «importancia suficiente» para justificar su determinación como violación manifiesta.

La cuestión de la «violación manifiesta» basada, inter alia, en la "gravedad» del acto de agresión, deberá armonizarse con lo establecido en el artículo $17^{27}$ del Estatuto de

\footnotetext{
27 El artículo 17 del Estatuto de Roma se lee así: «Artículo 17. Cuestiones de admisibilidad.

La Corte teniendo en cuenta el décimo párrafo del preámbulo y el artículo1, resolverá la inadmisibilidad de un asunto cuando: $[\ldots]$

d) El asunto no sea de gravedad suficiente para justificar la adopción de otras medidas por la Corte.»
} 
Roma, artículo que regula la admisibilidad de los asuntos relativos a cualquiera de los cuatro crímenes sobre los cuales la Corte tiene competencia. En efecto, el artículo 17.1.d impone a la Corte la obligación de declarar inadmisible un asunto que se le someta cuando, inter alia, "[e]l asunto no sea de gravedad suficiente para justificar la adopción de otras medidas por la Corte» (subrayado nuestro). De acuerdo con este artículo 17, la admisibilidad dependerá, entre otros requisitos, de una parte, que se trate de uno de los crímenes internacionales definidos en los artículos correspondientes del Estatuto de Roma y, de otra parte, que dicho crimen revista una "gravedad suficiente». La exigencia "gravedad suficiente», según el artículo 17.1, se justifica en el décimo párrafo del preámbulo y en lo dispuesto por el artículo 128 . Podemos concluir, del análisis del artículo 17, que la "gravedad suficiente» no es un elemento del tipo penal, sino un criterio de admisibilidad. En otros términos, la Corte podrá declarar inadmisible un asunto en vista de no revestir la "gravedad suficiente», sin que ello implique prejuzgar sobre la comisión o no de un crimen internacional de acuerdo con los tipos penales establecidos en el Estatuto de Roma.

Si efectuamos una comparación entre las expresiones «violación manifiesta» (artículo 8 bis) y "gravedad suficientes» (artículo 17.1.d), podemos concluir que:

*La primera expresión es constitutiva del tipo penal, sin cuya realización no nos encontramos ante un crimen de agresión en los términos del Estatuto de Roma.

*La segunda expresión es un requisito de admisibilidad que no afecta la naturaleza jurídica del crimen internacional.

En cuanto a la víctima, esta es, de una parte, el Estado que sufre el acto de agresión, toda vez que dicho acto afecta su soberanía, integridad territorial o independencia política (numeral 2 del artículo 8 bis) y, de otra parte, también la comunidad internacional que se ve afectada por el acto de agresión en cuanto vulnera o amenaza la paz, bien jurídico fundamental de acuerdo con la Carta de las Naciones Unidas (artículos 1.1, 2.4 y 2.6) ${ }^{29}$.

En cuanto al dolo, se requiere un dolo especial relativo a dos aspectos según los elementos de los crímenes. En primer lugar, debe el autor tener conocimiento que el uso de la fuerza armada en el caso en cuestión es incompatible con la Carta de las

\footnotetext{
28 El artículo 1 de Estatuto de Roma dice así: «Artículo 1. La Corte. Se instituye por el presente una Corte Penal Internacional («la Corte»). La Corte será una institución permanente, estará facultada para ejercer su jurisdicción sobre personas respecto de los crímenes más graves de trascendencia internacional de conformidad con el presente Estatuto y tendrá carácter complementario de las jurisdicciones penales nacionales. La competencia y el funcionamiento de la Corte se regirán por las disposiciones del presente Estatuto».

29 Carta de las Naciones Unidas: «Artículo 1. Los Propósitos de las Naciones Unidas son: 1. Mantener la paz y la seguridad internacionales, y con tal fin: tomar medidas colectivas eficaces para prevenir y eliminar amenazas a la paz, y para suprimir actos de agresión u otros quebrantamientos de la paz [...].»
} 
Naciones Unidas y, en segundo lugar, debe tener conocimiento que el acto de agresión en el caso en cuestión, por sus características, constituye una «violación manifiesta» de la Carta mencionada ${ }^{30}$. Esta suerte de flagrante violación de la Carta de la ONU hace que «el autor haya tenido conocimiento de las circunstancias de hecho que determinaban la incompatibilidad de dicho uso de la fuerza armada con la Carta de las Naciones Unidas» (numeral 6 del anexo II, enmiendas a los elementos de los crímenes). Es de recordar que, en el numeral 1 del artículo 8 bis, se establece que el acto de agresión imputable al autor debe constituir «una violación manifiesta de la Carta de las Naciones Unidas».

\section{La competencia de la Corte Penal Internacional respecto del crimen de agresión se activa a partir del 17 de julio de 2018.}

La Resolución ICC-ASP/16/Res.5, denominada «Activación de la competencia de la Corte respecto del crimen de agresión", fue adoptada por consenso en la 16ta Asamblea de Estados Partes en el Estatuto de Roma, el 14 de diciembre de 2017. La resolución establece claramente, en cuanto a la fecha de activación de la competencia, que la Asamblea:

1. Decide activar la competencia de la Corte sobre el crimen de agresión a fecha (sic) 17 de julio de 2018.

La Corte, de conformidad con la Resolución 5 (2017), podrá ejercer su competencia respecto del crimen de agresión a partir del 17 de julio 2018, respecto de los Estados Partes en el Estatuto de Roma "que hayan aceptado las enmiendas [aprobadas en Kampala], un año después de haber depositado sus instrumentos de ratificación o aceptación» (numeral 2) ${ }^{31}$. La misma resolución precisa que la Corte no podrá ejercer su competencia en ningún caso, salvo remisión por el Consejo de Seguridad ${ }^{32}$,

30 «Anexo II. Enmiendas a los elementos de los crímenes

Artículo 8 bis Crimen de agresión [...]

Elementos [...]

4. Que el autor haya tenido conocimiento de las circunstancias de hecho que determinaban la incompatibilidad de dicho uso de la fuerza armada con la Carta de las Naciones Unidas. [...]

6. Que el autor haya tenido conocimiento de las circunstancias de hecho que constituían dicha violación manifiesta de la Carta de las Naciones Unidas.»

31 Respecto del ejercicio de la competencia personal y territorial de la Corte, la Resolución 5 (2017) estableció: «2. Confirma que, de conformidad con el Estatuto de Roma, las enmiendas al Estatuto relativas al crimen de agresión adoptadas en la Conferencia de Revisión de Kampala entran en vigor para aquellos Estados Partes que hayan aceptado las enmiendas un año después de haber depositado sus instrumentos de ratificación o aceptación y que en caso de remisión de un Estado o de investigación motu proprio, la Corte no ejercerá su competencia en relación con el crimen de agresión cuando este haya sido cometido por nacionales o en el territorio de un Estado Parte que no haya ratificado o aceptado dichas enmiendas".

32 Según el artículo 13, literal b, del Estatuto de Roma: «la Corte podrá ejercer su competencia respecto de cualquiera de los crímenes a que se refiere el artículo 5 [...) si: [... b) el Consejo de Seguridad actuando en con arreglo 
cuando el crimen de agresión «haya sido cometido por nacionales o en el territorio de un Estado Parte que no haya ratificado o aceptado dichas enmiendas» (numeral 2, precitado). En consecuencia, la Corte ejercerá su competencia, respecto del crimen de agresión, únicamente en los casos que un Estado Parte en el Estatuto de Roma y que ha ratificado o aceptado las enmiendas adoptadas en Kampala, sea víctima de una agresión, o si uno de sus nacionales es acusado de dicho crimen.

De conformidad con los artículos 13, literal $b, 12$ y 5 del Estatuto de Roma, quien puede hacer realidad el alcance universal de la sanción penal respecto del crimen de agresión —así como respecto de los crímenes de Genocidio, de Lesa Humanidad y de Guerra- es el Consejo de Seguridad. El Consejo de Seguridad está habilitado a presentar, según los artículos precitados, ante el Fiscal de la Corte una situación en que parezca haberse cometido uno o varios de esos crímenes, aun en los casos en que el Estado concernido no sea Estado Parte en el Estatuto de Roma, o que no hubiera ratificado o aceptado las enmiendas aprobadas en Kampala. Si el Consejo de Seguridad así procediera, realizaría una contribución muy importante a fin de lograr la paz en el mundo y contribuiría, también, a evitar miles de muertes y de otras atrocidades que lamentamos actualmente en diversas partes del mundo.

\section{Referencias}

Blasi, T., Reyes, M. y León Vega, M.R. (Comps.) (2008). Derecho internacional humanitario. Compilación de instrumentos. Lima: Comisión Nacional de Estudio y Aplicación del Derecho Internacional Humanitario (CONADIH).

Burneo, J. (2017). Derecho Penal Internacional. Genealogía de los crimenes internacionales más graves. Lima: Fondo Editorial de la PUCP.

Comisión de los Quince. (1919). Rapport présenté à la conférence des préliminaires de paix de 1919 par la Commission des responsabilités des auteurs de la guerre et sanctions. Naciones Unidas document A/CN.4/7/Rev. 1 du 27 mai 1949. Nueva York: Lake Success.

David, Eric (2009). Éléments de Droit Pénal International et Européen. Bruselas: Bruylant.

International Law Association. (1925). Report of the Thirty-Third Conference held at The Riddarhuset and at The Riksdaghuset, Stockholm, September 8th to 13th, 1924. Londres: Sweet \& Maxwell.

International Law Association (1927). Report of the Thirty-Fourth Conference held at The Imperial Palace and at The Chamber of Commerce, Vienna, August 5th to 11th, 1926. Londres: Sweet \& Maxwell.

Mérignhac, A. (1912). Traité de droit public international. Volumen I. París: Edit. LGDJ.

Nys, E. (1906). Le droit international. Bruselas-París: Éditeurs A. Castaigne et A. Fontemoing.

a lo dispuesto en el Capítulo VII de la Carta de las Naciones Unidas, remite al Fiscal una situación en que parece haberse cometido uno o varios de esos crímenes." 
Pella, V. (1925). La criminalité collective des États et le droit pénal de l'avenir. Bucarest: Imprimerie de l'Etat.

Samón, E. y Bazay, L. (2011). El crimen de agresión después de Kampala: soberanía de los Estados y lucha contra la impunidad. Lima: Instituto de Democracia y Derechos Humanos (IDEH-PUCP) de la Pontificia Universidad Católica del Perú.

Tribunal de Núremberg. (1947). Procès des grands criminels de guerre devant le Tribunal Militaire International. Nuremberg, 14 de novembre de 1945 - 1 d'octobre de 1946. Núremberg: Secretaría del Tribunal.

Fecha de recepción: 16 de marzo de 2018 Fecha de aprobación: 22 de junio de 2018 